\title{
Prevalence of exclusive breastfeeding practice in Ethiopia and its association with maternal employment: a systematic review and meta- analysis, 2019.
}

Getu Engida Wake ( $\sim$ getuengida120@gmail.com )

Debre Berhan University

Yohannes Moges Mittiku

Debre Berhan University

Research article

Keywords: Prevalence, Exclusive breastfeeding, Meta-analysis, maternal employment, Ethiopia.

Posted Date: June 24th, 2020

DOI: https://doi.org/10.21203/rs.3.rs-33572/v1

License: (a) This work is licensed under a Creative Commons Attribution 4.0 International License.

Read Full License 


\section{Abstract}

Background: Exclusive breastfeeding defined as the practice of providing only breast-milk for an infant for the first 6 months of life without the addition of any other food or water, which recommends initiation of breastfeeding within one hour of life and continued breastfeeding for up to 2 years of age or more. Maternal employment is the most important factor contributing to the low practice of exclusive breastfeeding. However; the effect of maternal employment on exclusive breastfeeding is not investigated in Ethiopia.

Methods: Preferred Reporting Items for Systematic Reviews and Meta-Analyses (PRISMA) guideline was used in this systematic review and meta-analysis. The databases used were; PubMed, Google Scholar, Science Direct, and Cochrane library were systematically searched. Joanna Briggs Institute Meta-Analysis of Statistics Assessment and Review Instrument (JBI-MAStARI) was used for critical appraisal of studies.

Results: thirty-six studies were included in the final analysis after reviewing 541 studies in this metaanalysis yielding the pooled prevalence of EBF 59.76\% (95\% Cl: $54.84,64.68)$ in Ethiopia.

Those employed mothers were $57 \%$ less likely to practice exclusive breastfeeding in comparison to unemployed mothers in Ethiopia [OR] 0.43; $95 \% \mathrm{Cl}(0.3,0.62)$.

Conclusions: The overall prevalence of exclusive breastfeeding in this meta-analysis is low in comparison to the global recommendation of the practice of exclusive breastfeeding. Maternal employment was significantly associated with the practice of exclusive breastfeeding in comparison to their counterparts. Based On our review findings, we recommended that the Ethiopian government should increase legislated paid maternity leave after delivery beyond current paid maternity leave and implement policies that empower women and create a conducive environment for mothers to practice exclusive breastfeeding at the workplace.

\section{Background}

Breast milk is the natural food for newborns and reduces infant mortality and morbidity. Breast milk also helps the newborn to attain normal growth and development. Not only for neonatal health but also breastfeeding has health benefits for mothers and it plays a great role in improving public health [1-3].

To help newborn get appropriate growth and development, in 2001(WHO) set up the recommendation that declares that mothers from both low income and high-income countries should exclusively breastfeed their infants for the first 6 months of life, and then make sure that the infants receive adequate and nutritious semi-solid foods in addition to breastfeeding until the infant reaches 2 years of age or more $[4,5]$.

Exclusive breastfeeding (EBF) defined as the practice of providing only breast-milk for an infant for the first 6 months of life without the addition of any other food or water, which recommends initiation of 
breastfeeding within one hour of life and continued breastfeeding for up to 2 years of age or more accordingly. Exclusive breastfeeding (EBF) is the foundation of child survival and child health.it helps as a child's first immunization which used for protection from respiratory infections, diarrheal disease, and other potentially life-endangering problems. Besides these Exclusive breastfeeding protects maternal obesity and certain non-communicable diseases later in her life [6, 7].

One of the targets of sustainable development goal (SDG) that was set in 2015 was to reduce the global maternal mortality ratio to less than 70 per 100,000 live births and to reduce neonatal mortality to at least as low as 12 per 1,000 live births and under 5 mortality to at least as low as 25 per 1,000 live births by 2030[8].

But still, we are far behind to make exclusive breastfeeding during the first 6 months of life the norm for infant feeding. Currently, the worldwide prevalence of EBF for infants aged $0-6$ months is only $38 \%$. Different researchers indicate that $11.6 \%$ of mortality in children under 5 years of age was contributed by non-exclusive breastfeeding which was equivalent to about 804000 child deaths in 2011[9,10].

In 2012, the World Health Assembly endorsed a Comprehensive implementation plan on the maternal, infant, and young child nutrition with specified six global nutrition targets for 2025 and from this, the fifth target states that, to increase the rate of exclusive breastfeeding in the first 6 months up to $50 \%$. In 2018 , only 31 of 194 countries were on the line to meet the global target of exclusive breastfeeding, which aims to increase the prevalence of exclusive breastfeeding to $50 \%$ for the infants under 6 months by $2025[11,12]$.

According to 2015 UNICEF, Breastfeeding Advocacy Initiative For the best start in life report, the rate of EBF is low with the aimed goal of 2015.accordingly the rate of EBF is $(25,30,47,32,51,46,38) \%$ in western and central Africa, East Asia and Pacific, South Asia, Central America and the Caribbean, eastern and southern Asia, least developed countries and worldwide respectively[13].

During the years between 1985 and 1995, global rates of exclusive breastfeeding raised by $2.4 \%$. Twentyfive countries raised their rates of exclusive breastfeeding by $20 \%$ or more after $1995[14,15]$.

In addition to the above Cambodia and Malawi showed an increment of exclusive breastfeeding (EBF) from ( 11 to 74$) \%$ and (3 to 71) \% respectively for infants less than 6 months between (1992 - 2010) [16].

Another study conducted in 13 western African countries and sub-Saharan countries showed the prevalence of exclusive breastfeeding for infants under 6 months of age ranges from $13.0 \%$ in Côte d'Ivoire to $58.0 \%$ in Togo and $45.2 \%$ in sub-Saharan countries respectively[17,18].

According to the result of the 2016 Ethiopian demographic health survey (EDHS), the prevalence of exclusive breastfeeding for infants under 6 months was $58 \%$ [19].

Worldwide around 600,000 children and 100,000 women die each year because of complications that could easily be prevented with breastfeeding. Besides this Millions of dollars have been lost to treat 
children with different health problems such as diarrhea and pneumonia that can easily be prevented with only exclusive breastfeeding [20].

Globally 595379 childhood deaths among ( 6 to 59 ) months of age from diarrhea and pneumonia each year were associated with the problem of not breastfeeding according to global recommendations of WHO and UNICEF for breastfeeding [21].

According to a study conducted In Latin America and the Caribbean countries, exclusive breastfeeding for the first 3 months of life can prevent $55 \%$ of infant deaths related to diarrheal disease and acute respiratory infection [22].

A study conducted in Bangladesh showed that Infants who were partially breastfed or not breastfed had a risk of diarrheal death 3.94 times greater than those exclusively breastfed infants [23]. Globally, more than 1.45 million lives were lost due to suboptimal breastfeeding in developing countries [24].

A study conducted in Ghana showed that the risk of neonatal death was fourfold higher in children given milk-based fluids or solids in addition to breast milk in comparison to those fed breast milk exclusively according to WHO recommendation [25].

According to the Federal Democratic Republic of Ethiopia, the Ministry of Health report, In Ethiopia up to 70,000 infant deaths were associated with problems of nonexclusive breastfeeding [26].

Inadequate rates of exclusive breastfeeding result from different factors. These factors include Inadequate maternity and paternity leave legislation that enforces the mothers returning early to work and other workplace policies that don't support a woman's ability to breastfeed when she returns to work plays a great role.

In addition to the above factors, caregiver and societal belief which favor nonexclusive breastfeeding before 6 months of age also affect adequacy and quality of exclusive breastfeeding.

To attain progress on the global exclusive breastfeeding target by 2025 women should be empowered to practice exclusively breastfeed, by providing 6 months of mandatory paid maternity leave [27].

Breastfeeding and work shouldn't be a dilemma for employed women. They should not have to decide between breastfeeding and working. The International Labour Organization states that countries should enact legislation giving women the right to 18 weeks of paid maternity leave and make sure that women have time and adequate space for continuing breastfeeding when they return to work [28].

Countries are expected to make policies that create a conducive environment for breastfeeding in the workplace and help women to breastfeed their children exclusively for the first 6 months and thereafter. Some Evidence shows that longer maternity leave helps the mothers to practice exclusive breastfeeding more as per WHO recommendations [29]. 
The governments of India and Viet Nam have been successfully protecting exclusive breastfeeding by the implementation of supportive policies that guarantee mothers to get six months' paid maternity leave.in addition to the above, both countries place strong legislation that prohibits the use of marketing breast milk substitutes, bottles, and teats before 6 months of infants age[30,31].

But, contrary to WHO recommendation, the Constitution of Ethiopia and Labour Proclamation, recommends employed mothers to get fully paid maternity leave of 120 working days only (30 days antenatal and 90 days postnatal) on the recommendation of the medical doctor and the proclamation doesn't support women to breastfeed in the workplace and the public area after they return to work which has its effect on good practice of exclusive breastfeeding [32].

In Ethiopia, many studies have been conducted to determine the prevalence of exclusive breastfeeding (EBF) and its associated factors between January 1/2015 to October 30/2019.

But the findings of these different studies documented that there was great variability in the prevalence of EBF across the regions of the country during the mentioned year in the above.

Concerning associated factors, these studies showed that different maternal and health service-related factors influenced EBF;

Maternal employment [33-50],Mode of delivery [34,39,41,42,43,45,50-54],Marital status[33,34,41,42,47,55,56,57],colostrum feeding[35,37,38,43,58,59,60,61],prelacteal feeding[ $34,38,43,55,57,62]$,age of mother[63,64,65,66,67], place of delivery $[34,39,56,68]$ were some of the associated factors with practice of exclusive breast feeding(EBF).

From the above factors, we selected one factor (maternal employment) to investigate its effect on the practice of exclusive breastfeeding (EBF). We selected this factor because of the following reasons: The first reason is that maternal employment was the most important factor, which ultimately influencing EBF, especially in our country where the legislation of civil Service give only 4 months of paid maternity leave and enforce mother to return quickly to their job before 6 months after delivery. The second reason is that the primary studies conducted previously showed that controversial findings regarding the effect of maternal employment on EBF. among those primary studies some of them showed a negative association of maternal employment with exclusive breastfeeding with the presence of grate variation among them[33-38,41-50]and the rest studies showed a positive association of maternal employment with $\operatorname{EBF}[39,40]$. Because of the above-mentioned factors, we intended to undertake this meta-analysis. As far as our knowledge is concerned, Even if there were small and fragmented studies, there is no published systematic review and meta-analysis which investigated the pooled prevalence of exclusive breastfeeding and its association with maternal employment between January 1/2015 to October $30 / 2019$ which is in line with 3rd target of sustainable development goal by 2030 in Ethiopia. So, the purpose of this systematic review and meta-analysis was to estimate the pooled prevalence of EBF and its association with maternal employment in the context of Ethiopia. 
This Systematic review will generate concrete evidence that helps policymakers and program planners to make an appropriate intervention and remold some policies concerning maternal employment and practice of exclusive breastfeeding for the best benefits of mothers and infants in Ethiopia.

\section{Methods}

\section{Searching strategies}

The Preferred Reporting Items for Systematic Reviews and Meta-Analysis (PRISMA) [69] was used in our systematic review and meta-analysis to evaluate the pooled prevalence of exclusive breastfeeding practice and its association with maternal employment in the context of Ethiopia.

Databases, such as PubMed, Google Scholar, Science Direct, and Cochrane library were used for searching. ("exclusive breastfeeding" OR "Feeding, Breast"[MeSH Terms] OR "Breastfeeding"[MeSH Terms] OR "Breast Feeding, Exclusive"[MeSH Terms] OR "Exclusive Breast Feeding"[MeSH Terms] OR "Breastfeeding, Exclusive"[MeSH Terms] OR "Exclusive Breastfeeding"[MeSH Terms] AND ("factors" OR "determinants") AND Ethiopia was some of the search keywords in this systematic review and metaanalysis research.

The above terms were applied individually and together with each other using Boolean operators like "OR" or "AND". We performed this search from September 11/2019 to October 30, 2019. The whole number of primary studies published until October 30,2019 , were used in this systematic review and meta-analysis.

\section{Eligibility criteria}

\section{Inclusion criteria:}

- Only studies conducted in Ethiopia.

- All papers published in peer-reviewed journals.

- Any observational study design such as Cross-sectional, case-control, and cohort which report the prevalence of EBF or associations between maternal employments with EBF were considered.

- All primary papers that reported necessary information on the prevalence of exclusive breastfeeding or the primary studies reported data on the association of maternal employment with exclusive breastfeeding were included.

- All primary studies stated in the English language were included.

- Only studies published from January $1 / 2015$ to October 30/2019 were considered.

\section{Exclusion criteria}

- Study Conducted in women with HIV/AIDS, preterm newborns, and newborns in an intensive care unit were excluded.

- Study with abstracts without full text and Qualitative studies, symposium/conference, case reports. 
- Primary studies, which were not obtained, even if the investigator made repetitive Email contact.

\section{Outcome measurement}

The primary outcome of this review was the Prevalence of Exclusive Breastfeeding practice among mothers with infants less than 6months. Exclusive breastfeeding (EBF) is defined as the practice of providing only breast-milk for an infant for the first 6 months of life without the addition of any other food or water, except for vitamins, mineral supplements, or medicines [6]. The other outcome was to investigate the association between maternal employment and exclusive breastfeeding and we calculated the log odds ratio based on the results of the primary studies.

Data extraction: Standardized data extraction format, which was adopted from the JBI data extraction format was applied. Two authors (GE and YM) independently collected all the needed information. Any unclear information and disagreement which arises between the

Reviewers during data abstraction were resolved through discussion and concurrence. Data was collected on the following variables: primary author, publication year, and study Area, study design, sample size, the prevalence of exclusive breastfeeding, and the quality score of primary studies.

Quality assessment: The Joanna Briggs Institute Critical Appraisal tools for use in JBI Systematic Reviews (JBI-MAStARI) was used for critical appraisal of primary studies [70].The tool has 8 major criteria for critical appraisal of each primary study. Accordingly primary studies with a score of $50 \%$ and above included in the Meta-analysis research.

Statistical analysis and methods: Data were interred in Microsoft Excel, then exported to STATA version 11 software for further analysis. Heterogeneity concerning reported prevalence was assessed by computing p-values for Cochrane Q-statistics and I2 tests and I 2 test statistics of $25 \%, 50 \%$, and $75 \%$ were declared as low, moderate, and high heterogeneity respectively [71].

The pooled prevalence of exclusive breastfeeding with a 95\% confidence interval (Cl) in this metaanalysis was presented with the Forest plot. Besides, subgroup analysis was done by the publication year of primary studies and an administrative area (region) in Ethiopia. We checked Publication bias by funnel plot and Egger's and Begg's tests subjectively and objectively respectively and a p-value less than 0.05 was used to declare the statistical significance of publication bias [72]. Ln odds ratio was applied to examine the association between maternal employment and EBF in Ethiopia.

\section{Results}

As described in Fig. 1, 541 studies were identified regarding EBF in Ethiopia through PubMed, Google Scholar, Science Direct, and others initially. Then 90 studies were excluded because of duplication. From the remaining 451 studies, 200 articles were excluded after reviewing their titles based on assessment 
because of a lack of relevance to the current study. The rest 251 records were screened by abstracts and this made 198 records to be excluded. Furthermore, 53 full-text records were screened for the fulfillment of the stated inclusion criteria. After all 17 articles were excluded due to lack of fulfillment of inclusion criteria. Amid excluded studies, three of the studies were excluded because of missing of the outcome of interests [73, 74, 75]. Two studies conducted among HIV infected mothers [76, 77]. The rest 12 articles were excluded because of publication year; one Study published in 2009[78], two studies were published in 2012[79,80],three of the studies were published in 2013[81,82,83],six studies were published in $2014[84,85,86,87,88,89]$. Eventually, 36 studies included in the systematic review and meta-analysis after we checked for inclusion criteria.

As displayed in Additional file1: Table S1, entire of these thirty-six studies were published between January $1 / 2015$ to October 30/2019. A total of 27907 breastfeeding women were included in our Metaanalysis and systematic review. Thirty-three of the studies were cross-sectional study design. The lowest and highest sample size included the studies found between 226 and 5,227 respectively. A study conducted in Addis Ababa, Ethiopia (29.29\%) [54], and a study conducted in Bahir dar, Amhara Region, Ethiopia (86.44\%) [35] Reported lowest and highest prevalence of exclusive breastfeeding respectively. From nine an administrative area (regions) of Ethiopia, primary studies from seven administrative areas and one council city were included in this meta-analysis.

Among all of included primary studies, Twelve of these studies were from Amhara [34-43,55,68], two from Addis Ababa [52,53], three from Affar [33,58,63], three from Oromia [45,64,65], twelve from SNNP [46-48,51,52, 54,57, 59, 60,61,62,66], one from Tigray [67], one from Somalia[49],one from Harari[44]and one from nationwide[50]. We didn't find any study representing Benishangul Gumiz,Gagmbela and Dire dawa council city in this review research. Regarding the quality score of each primary study, the score was between the lowest 4 and highest 8 .

\section{Meta-analysis}

\section{Pooled Prevalence of exclusive breastfeeding in Ethiopia}

The pooled prevalence of EBF in Ethiopia from 36 included studies is 59.76\% (95\% Cl: $54.84-64.68$ ) (fig.2). The I2 test result indicated high heterogeneity among included studies (I2 98.7\%, $p=<0.000$ ), because of this high heterogeneity the random effect model was used. In our review research, Belachew et al $(86.44 \%)$ and shiferaw et al $(29.29 \%)$ reported the highest and lowest prevalence of exclusive breastfeeding respectively (fig.2).

\section{Subgroup analysis}

A subgroup analysis was done by an administrative area (region) in Ethiopia and the year of publication to compare the prevalence of exclusive breastfeeding across different studies. This systematic review and meta-analysis showed that the highest prevalence reported in a study conducted in Somalia $71.16 \%$ (95\% Cl: 67.39, 74.91) (Table.2) and a study published during (2015-2016) $64.60 \%(52.90,76.30)$ (fig.3). 
Table 2. The subgroup analysis for the prevalence of exclusive breastfeeding by administrative area (region) in Ethiopia, $2019(\mathrm{n}=36)$

\begin{tabular}{l|l|l|l|l|l|}
\hline bles & Characteristics & Number of Included study & Prevalence (95\% CI) & I2 & p-value \\
\hline \multirow{6}{*}{ gion } & Addis Ababa & 2 & $36.84(22.02,51.26)$ & $95.8 \%$ & $<0.001$ \\
\cline { 2 - 6 } & Affar & 3 & $70.01(53.36,86.66)$ & $98.8 \%$ & $<0.001$ \\
\cline { 2 - 6 } & Amhara & 12 & $58.81(49.58,70.04)$ & $99.2 \%$ & $<0.001$ \\
\cline { 2 - 6 } & Harari & 1 & $40.94(36.27,46.62)$ & - & - \\
\cline { 2 - 6 } & Nationwide & 1 & $59.91(58.36,61.46)$ & - & - \\
\cline { 2 - 6 } & Oromia & 3 & $66.47(40.21,90.71)$ & $99.4 \%$ & $<0.001$ \\
\cline { 2 - 6 } & SNNP & 12 & $59.31(52.49,66.14)$ & $96.8 \%$ & $<0.001$ \\
\cline { 2 - 6 } & Somalia & 1 & $71.16(67.39,74.91)$ & - & - \\
\cline { 2 - 6 } & Tigray & 1 & $70.19(66.29,74.08)$ & - & - \\
\hline
\end{tabular}

Association between maternal employment and exclusive breastfeeding in Ethiopia: in this review, we assessed the association between maternal employment and EBF practice using eighteen primary studies [33-50]. The final finding of these primary studies indicated that the practice of EBF was significantly associated with maternal employment. Those employed mothers were $57 \%$ less likely to practice exclusive breastfeeding in comparison to unemployed mothers [OR] 0.43 (95\% Cl: 0.3-0.62) (fig.4).

A random-effect model was applied to examine the association between maternal employment and EBF in Ethiopia since High heterogeneity $(12=85.8 \%$ and $p$-value $<0.000)$ was observed across the included records.

We also assessed publication bias subjectively using the funnel plot and objectively using Begg's and Egger's tests respectively in this meta-analysis. Even if the funnel plot showed the presence of publication bias, Begg's and Egger's tests showed the absence of significant publication bias ( $p$-value $>0.544$ and $\mathrm{p}=0.190$ ) respectively (fig.5).

\section{Discussion}

To our knowledge, this is the first systematic review and meta-analysis research examining the impact of maternal employment on exclusive breastfeeding in Ethiopian using a study published between 2015 -2019. The main aim of this systematic review and meta-analysis research was to estimate the pooled prevalence of exclusive breastfeeding and its association with maternal employment in Ethiopia among study conducted between January 1/2015 and October 30/2019.

Breastfeeding is core is part of the 2030 Agenda for Sustainable Development goal which is linked with many targets of Sustainable Development Goals (SDGs) especially with 3rd target which deals with ending preventable maternal and neonatal death [8]. This type of meta-analysis plays a great role for program planners and policymakers to make all mothers practice optimum breastfeeding practice in Ethiopia according to WHO recommendation and helps to end preventable maternal and neonatal death. 
According to the results of 36 studies included in this meta-analysis the pooled prevalence of exclusive breastfeeding in Ethiopia is $59.76 \%(95 \% \mathrm{Cl}=54.84,64.68)$.

The overall prevalence of exclusive breastfeeding in this study is almost similar with the result of the 2016 Ethiopian demographic and health survey (EDHS) result (58\%) [19] And the result of a metaanalysis conducted in Ethiopia (59.31\%) [90].This similarities could be attributed to similarities in sociodemographic, methodological, and the characters of individual studies included in both review and EDHS reports. The overall reported prevalence of EBF in this review is higher than the result of meta-analysis result conducted in Iran(49.1\%)[91] and 29 sub-Saharan African countries, which showed the prevalence of EBF (23.70\% in Central Africa) and (56.57\% in Southern Africa)[92]. The pooled prevalence in this review is also higher than the results of the study conducted in 27 sub-Saharan African countries (SSA) (36\%) [93], Demographic and health survey of Tanzania (22.9\%) [94], demographic and health survey of Madagascar (48.8\% [95] and study conducted in developing countries (39\%) [96].

This variation might be because of methodological differences, differences in infants and maternal socio-demographic characteristics, economical, health service utilization, the gap of the year at which the study was conducted, and the number of studies included in the review.

Again the overall prevalence of exclusive breastfeeding in this research is much higher than the results of primary study conducted in Bangladesh(5\%)[97], Southern Brazil (43.7\%)[98], Lebanon (27.4\%)[99], Al Hassa, Saudi Arabia (12.2\%)[100], Tamil Nadu India (34\%)[101], Canada (15.3\%)[102],Tabuk Saudi Arabia (31.4\%)[103]. This difference might be because of methodological differences and differences in health service utilization and health service coverage. But the overall prevalence exclusive breastfeeding in our review is lower than the result of the primary study conducted in Indian regains, which indicated the prevalence of exclusive breastfeeding was $79.2 \%$ in southern India and $68.0 \%$ in northeastern India )respectively(104), Nepal demographic and health survey result (66.3\%)[105], and the result of the study conducted in Ghana (64\%)[106].

Besides, we performed sub-group analysis based on the study areas or Regions in Ethiopia where the studies were conducted and year of publication of the primary studies. Accordingly, the highest $(71.16 \%)$ and lowest (36.84\%) prevalence of exclusive breastfeeding was reported in a study conducted in Somalia and Addis Ababa City respectively. This regional difference of prevalence of exclusive breastfeeding might be because of differences in socio-demographic, the difference in numbers of the study included the two regions during analysis. In addition to the above, in the study conducted in the Somalia region, a large number of study participants were unemployed mothers and according to different literature, unemployment is associated with a high prevalence of exclusive breastfeeding practice [41, 84].

We also performed a subgroup analysis using a year of study publication. Accordingly, the highest (64.60\%) and lowest (57.05\%) prevalence of exclusive breastfeeding were reported in the study published during 2015-2016 and 2017-2019 respectively. This difference could be attributed to the difference in coverage of health information regarding exclusive breastfeeding and effective utilization of health 
extension workers, adherence to the national and international policy by health institutions [107]. Also, this difference might be attributed to the number of studies included in each category during analysis.

Maternal employment was significantly associated with exclusive breastfeeding in this systematic review and meta-analysis research. Accordingly, Employed mothers were $57 \%$ less likely to practice exclusive breastfeeding as compared to unemployed mothers. This result is in line with the results of the primary study conducted in Lebanon [99], a study conducted in Iran [108], a study conducted in Malaysia [109], a study conducted in Saudi Arabia [103] and the study conducted in Somalia [110].

This similarity could be attributed to Mothers who returned to work at an earlier time before 6 months have less frequency of contact with their baby and employed mothers begin liquid and solid based supplementation of food before the expected age of starting weaning food which will end up with the decreased practice of exclusive breastfeeding [111].

Some evidence showed that employed mothers face unique barriers to practice exclusive breastfeeding and returning to work too early after the birth has been shown to harm the practice of exclusive breastfeeding.one study showed that the more we increase the legislated duration of paid maternity leave, the more the mothers practice exclusive breastfeeding and this will result in a higher prevalence of exclusive breastfeeding $[112,113,114]$.

Limitations of the study: like other studies, our systematic review and meta-analysis research has some limitation. Among these; majorities of the primary study included in the review were cross-sectional study which might affect the outcome variable because of other confounding factors, studies published in a language other than English were not included in the review, the review addressed only one associated factor (maternal employment) on exclusive breastfeeding and the last limitation is that the review included some studies with small sample size which might affect the pooled report of exclusive breastfeeding.

\section{Conclusions}

The overall prevalence of exclusive breastfeeding in this meta-analysis is low in comparison to the global recommendation of the practice of exclusive breastfeeding.

Maternal employment was significantly associated with the practice of exclusive breastfeeding in comparison to their counterparts. Based On our review findings, we recommended that the Ethiopian government should increase legislated paid maternity leave after delivery beyond current paid maternity leave and implement policies that empower women and create a conducive environment for employed mothers to practice exclusive breastfeeding at the workplace.

\section{Abbreviations}


AIDS: Acquired Immune Deficiency Syndrome; Cl: Confidence Interval; EBF: Exclusive breastfeeding; EDHS: Ethiopian demographic health survey; HIV: Human immunodeficiency virus; HSTP: Health Sector

Transformation Plan; JBI: Joanna Briggs Institute; JBI-MAStARI: Joanna Briggs Institute Meta-Analysis of Statistics Assessment and Review Instrument; MMR: Maternal mortality ratio; NM: Neonatal mortality; OR: Odds ratio; PRISMA: Preferred Reporting Items for Systematic Reviews and Meta-Analyses; SDG: sustainable development goal; SNNP; Southern Nations, Nationalities, and Peoples'; SSA: Sub Saharan African; UNICEF: United Nations International Children's Emergency Fund; WHO: world health organization.

\section{Declarations}

\section{Ethics approval and consent to participate}

Not applicable

Consent for publication

Not applicable

\section{Availability of data and materials}

Datasets used for this study and other supplementing materials are available from the corresponding author on request.

\section{Competing interests}

The authors declare that they have no competing interests.

\section{Funding}

No, any funding was received from any organization.

\section{Authors' contributions}

GE: Conception of the research protocol, study design, literature review, data extraction, data analysis, interpretation, and drafting of the manuscript.YM: data extraction, quality assessment, data analysis, and reviewing the manuscript. Both authors have read and approved the manuscript.

\section{Acknowledgments}

Not applicable

\section{References}


1. World health organization(WHO).World Breastfeeding Week, Protect Breastfeeding in the Workplace; Pan Am Heal Organ. (2019):1-6.

2. Gupta PM, Perrine CG, Chen J, Elam-evans LD, Flores-ayala R, Activity P, et al.Monitoring the World Health Organization Global Target 2025 for Exclusive Breastfeeding: Experience From the United States. HHS public access.2017,33(3:):578-81.

3. Communicable disease control(CDC).Breastfeeding Report Card, Progressing Toward National Breastfeeding Goals. 2016:1-8.

4. Qasem W, Fenton T, Friel J.Age of the introduction of first complementary feeding for infants: a systematic review. BMC Pediatr [Internet]. 2015;15(107). Available from: http://dx.doi.org/10.1186/s12887-015-0409-5

5. World health organization (WHO)/ United Nations International Children's Emergency Fund(UNICEF).Global Strategy for Infant and Young Child Feeding,Geneva.2003.

6. World health organization (WHO).Infant and young child feeding,Model Chapter for textbooks for medical students and allied health professionals. 2009.

7. World health organization (WHO).Long-term effects of breastfeeding,Systematic review. 2013.

8. UNITED NATIONS.Transforming our world,the 2030 agenda for sustainable development.2015. Available from: sustainabledevelopment.un.org.

9. Black RE, Walker S, Bhutta Z, Grantham-mcgregor S.Long-term metabolic risk among children born premature or small for gestational age. Springer Nature.2016. Available from: www.nature.com/nrendo

10. World health organization (WHO).World health statistics,Geneva 27, Switzerland. 2013.

11. World health organization (WHO).SIXTY-FIFTH WORLD HEALTH ASSEMBLY,GENEVA.2012:21-6.

12. World health organization (WHO). Global Nutrition Targets 2015,Policy Brief Series. 2012;1-2.

13. World health organization (WHO)/ United Nations International Children's Emergency Fund (UNICEF).Breastfeeding Advocacy Initiative For the best start in life. 2015; Available from: www.unicef.org.

14. United Nations International Children's Emergency Fund (UNICEF).BREASTFEEDING ON THE WORLD AGENDA.2012:4-7.

15. WORLD HEALTH ORGANIZATION(WHO).Essential nutrition action:improving maternal,newborn,infant and young child health and nutrition,Geneva 27, Switzerland. 2013.

16. United Nations International Children's Emergency Fund (UNICEF).Improving Exclusive Breastfeeding Practices by using Communication for Development in Infant and Young Child Feeding Programmes.2011-2012.

17. African W, Agho KE, Ezeh OK, Ghimire PR, Uchechukwu OL, Stevens GJ, et al. Exclusive Breastfeeding Rates and Associated Factors in 13 "Economic Community of West African States" (ECOWAS) Countries. Nutrients,. 2019;11(3007). 
18. Ayuk TB, Bassogog CB, Nyobe C. The determinants of exclusive breastfeeding in Cameroon, SubSaharan Africa. Trends Gen Pr. 2018;1(3):1-6.

19. Ethiopian Demographic and health survey(EDHS).2016.

20. United Nations International Children's Emergency Fund (UNICEF). The Global Cost of Not Breastfeeding. alive and thrive,. 2019;1-4.

21. Walters DD, Phan LTH, Mathisen R.The cost of not breastfeeding,global results from a new tool. Heal Policy Planning.2019:407-17.

22. Betrán AP, Onís M De, Lauer JA, Villar J.Ecological study of effect of breast feeding on infant mortality in Latin America. BMG. 2001;323:1-5.

23. Arifeen S, Black RE, Antelman G, Baqui A, Caulfield L, Becker S, et al.Exclusive Breastfeeding Reduces Acute Respiratory Infection and Diarrhea Deaths Among Infants in Dhaka Slums. Pediatrics.2001.

24. Lauer JA, Betra AP.Deaths and years of life lost due to suboptimal breast-feeding among children in the developing world, a global ecological risk assessment. Public Health Nutr. 2006;9(6):673-85.

25. Edmond KM, Zandoh C, Quigley MA, Amenga-etego S, Owusu-agyei .Delayed Breastfeeding Initiation Increases Risk of Neonatal mortality.2005.

26. The Federal Democratic Republic of Ethiopia, Ministry of Health.National Newborn and Child Survival Strategy Document Brief Summary 2015/16-2019/20. 2015.

27. world health organization(WHO)/ United Nations International Children's Emergency Fund (UNICEF). Global Nutrition Targets 2025,Breastfeeding Policy Brief. 2012;1-8.

28. world health organization(WHO)/ United Nations International Children's Emergency Fund (UNICEF).GLOBAL BREASTFEEDING SCORECARD ,ENABLING WOMEN TO BREASTFEED THROUGH BETTER POLICIES AND PROGRAMMES. Glob BREAST Feed. 2018;(3).

29. United Nations International Children's Emergency Fund (UNICEF). Expanding Viet Nam 's Maternity Leave Policy to Six Months: An Investment Today in a Stronger, Healthier Tomorrow. 2012.

30. MINISTRY OF LAW AND JUSTICE.THE MATERNITY BENEFIT ( AMENDMENT ), A $n$ Act further to amend the Maternity Benefit,new delhi. 2017;4-5.

31. International Cooperation Department, Ministry of Labour, Invalids and Social Affairs of Vietnam. 2012;1-100.

32. Ahmad I.ETHIOPAIN Decent Work Check . Wagelndicator Found.2019.Available from: www.wageindicator.org\%0AWagelndicator

33. Tsegaye M, Ajema D, Shiferaw S, Yirgu R.Level of exclusive breastfeeding practice in remote and pastoralist community , Aysaita. Int Breastfeed J. 2019;6:1-15.

34. Asemahagn MA.Determinants of exclusive breastfeeding practices among mothers in azezo district, northwest Ethiopia: Int Breastfeed J [Internet]. 2016;1-7. Available from: http://dx.doi.org/10.1186/s13006-016-0081-x

35. Belachew A, Tewabe T, Asmare A, Hirpo D, Zeleke B, Muche D.Prevalence of exclusive breastfeeding practice and associated factors among mothers having infants less than 6 months old, in Bahir Dar, 
Northwest, Ethiopia: BMC Res Notes [Internet]. 2018;1-6. Available from: https://doi.org/10.1186/s13104-018-3877-5

36. Asfaw MM, Argaw MD, Kefene ZK.Factors associated with exclusive breastfeeding practices in Debre Berhan District, Central Ethiopia: Int Breastfeed J [Internet]. 2015;1-9. Available from: http://dx.doi.org/10.1186/s13006-015-0049-2

37. Sinshaw Y, Ketema K, Tesfa M.Exclusive Breast Feeding Practice and Associated Factors Among Mothers in Debre Markos Town and Gozamen District, East Gojjam Zone: J Food Nutr Sci. 2016.

38. Mekuria G, Edris M.Exclusive breastfeeding and associated factors among mothers in Debre Markos , Northwest Ethiopia: Int Breastfeed J . 2015;1-7.

39. Arage G, Gedamu H.Exclusive Breastfeeding Practice and Its Associated Factors among Mothers of Infants Less Than Six Months of Age in Debre Tabor Town, Northwest Ethiopia: Adv public Heal. 2016;2016.

40. Gebrie YF, Dessie TM, Jemberie NF.Logistic Regression Analysis of Exclusive Breastfeeding Practice among Mothers in Amanuel Town, Northwest, Ethiopia: Am J Data Min Knowl Discov. 2019;3(2):13-9.

41. Chekol DA, Biks GA, Gelaw YA, Melsew YA.Exclusive breastfeeding and mothers ' employment status in Gondar town , Northwest Ethiopia: Int Breastfeed J . 2017;1-9.

42. Hunegnaw MT, Gezie LD, Teferra AS. Exclusive breastfeeding and associated factors among mothers in Gozamin district, northwest Ethiopia: Int Breastfeed J . 2017;1-8.

43. Tewabe T, Mandesh A, Gualu T, Alem G, Mekuria G, Zeleke H.Exclusive breastfeeding practice and associated factors among mothers in Motta town , East Gojjam zone , Amhara Regional State, Ethiopia: Int Breastfeed Journal. 2017;1-7.

44. Iffa MT, Serbesa ML.Family Medicine \& Medical Science Research Assessment of the Influence of Mother 's Occupation and Education on Breastfeeding and Weaning Practice of Children in Public Hospital , Harari Regional State Ethiopia: Fam Med Med Sci Res. 2018;7(3).

45. Bayissa ZB, Gelaw BK, Geletaw A, Abdella A, Yosef A, Tadele K. KNOWLEDGE AND PRACTICE OF MOTHERS TOWARDS EXCLUSIVE BREASTFEEDING AND ITS ASSOCIATED FACTORS IN AMBO WOREDA WEST SHOA ZONE OROMIA REGION: Int J Res Dev Pharm L Sci. 2015;4(3).

46. Edris MM, Atnafu NT, Abota TL.Magnitude and Determinants of Exclusive Breast Feeding Among Children Age Less Than 23 Months in Bench Maji Zone, Southwest Ethiopia: Int J Pediatr Child Care. 2019.

47. Adugna B, Tadele H, Reta F, Berhan Y.Determinants of exclusive breastfeeding in infants less than six months of age: Int Breastfeed J . 2017;4-11.

48. Getahun EA, Hayelom DH, Kassie GG. Exclusive Breast Feeding Practice and Associated Factors in Kemba Woreda, Southern Ethiopia: Int J Sci Technol Soc. 2017;5(4):55-61.

49. Tadesse F, Alemayehu Y, Shine S, Asresahegn $H$, Tadesse T.Exclusive breastfeeding and maternal employment among mothers of infants from three to five months old in the Fafan zone, Somali regional state of Ethiopia: BMC Public Heal. 2019;1-9. 
50. Ahmed KY, Page A, Arora A, Ogbo FA.Trends and determinants of early initiation of breastfeeding and exclusive breastfeeding in Ethiopia: Int Breastfeed J . 2019;9:1-14.

51. Breastfeeding E, Minch A.Factors Associated with Exclusive Breastfeeding Practices at Arba Minch Town, South Ethiopia: Adv Res.2018.

52. Zone G.Levels and Predictors of Exclusive Breast Feeding among Rural Mothers with Children Age 012 Months: Int J Pediatr Neonatal Heal. 2017;1(3):77-88.

53. Elyas L, Mekasha A, Admasie A, Assefa E.Exclusive Breastfeeding Practice and Associated Factors among Mothers Attending Private Pediatric and Child Clinics, Addis Ababa, Ethiopia: Int J Pediatr. 2017.

54. Shifraw T, Worku A, Berhane Y.Factors associated exclusive breastfeeding practices of urban women in Addis Ababa public health centers, Ethiopia: Int Breastfeed Journal [Internet]. 2015;4-9. Available from: http://dx.doi.org/10.1186/s13006-015-0047-4.

55. Tariku A, Alemu K, Gizaw Z, Muchie KF, Derso T, Abebe SM, et al.Mothers ' education and ANC visit improved exclusive breastfeeding in Dabat Health and Demographic Surveillance System Site: PLOSONE [Internet]. 2017;1-13. Available from: http://dx.doi.org/10.1371/journal.pone.0179056

56. Bisrat Z.Factors Associated with Early Initiation and Exclusive Breastfeeding Practices Factors Associated with Early Initiation and Exclusive Breastfeeding Practices among Mothers of Infant 's Age Less Than 6 Months: J Pediatr Neonatal Care Factors. 2017.

57. Sonko A, Worku A.Prevalence and predictors of exclusive breastfeeding for the first six months of life among women in Halaba special woreda, Southern Nations, Nationalities and Peoples ' Region / SNNPR /, Ethiopia: Arch Public Heal [Internet]. 2015;1-11. Available from: http://dx.doi.org/10.1186/s13690-015-0098-4

58. Liben ML, Gemechu YB, Adugnew M, Asrade A, Adamie B.Factors associated with exclusive breastfeeding practices among mothers in dubti town , afar regional state, northeast Ethiopia: Int Breastfeed J [Internet]. 2016;1-6. Available from: http://dx.doi.org/10.1186/s13006-016-0064-y

59. Azeze GA, Gelaw KA, Gebeyehu NA, Gesese MM, Mokonnon TM.Exclusive Breastfeeding Practice and Associated Factors among Mothers in Boditi Town, Wolaita Zone, Southern Ethiopia: Int J Pediatr. 2019.

60. Surender.R T.Determinants of Exclusive Breastfeeding Practice among Mothers of Children Journal of Pregnancy and Child Health Determinants of Exclusive Breastfeeding Practice among Mothers of Children Under Two Years Old: J Pregnancy Child Heal. 2016.

61. Lenja A, Demissie T, Yohannes B, Yohannis M.Determinants of exclusive breastfeeding practice to infants aged less than six months in Offa district, Southern Ethiopia: Int Breastfeed J [Internet]. 2016;1-7. Available from: http://dx.doi.org/10.1186/s13006-016-0091-8.

62. Alemu.E,Wondoson.A ND.Prevalence and Determinants of Exclusive Breastfeeding Practices among Infants in Hossana Town, Southern Ethiopia: EC Gynaecol. 2017;3.

63. Gizaw Z, Woldu W, Bitew BD.Exclusive breastfeeding status of children aged between 6 and 24 months in the nomadic population of Hadaleala district, Afar Region, northeast Ethiopia: Int 
Breastfeed J . 2017;1-7.

64. Kitesa B, Bekele H.Assessment of Exclusive Breast-Feeding and Associated Factors Among Anti Natal Care ( ANC ) and Non-ANC Mothers in Upper Awash Basin of Ethiopia: Int J Clin Dev Anatomy. 2017;3(2):9-18.

65. S.Demelash,L.Oljira,M.Demena MT.Breastfeeding practice and associated factors among mothers / caretakers of children aged 0 - 23 months in Asella Town , South East Ethiopia: 2017;6(4).

66. T.Kelaye.Assessment of Prevalence of Exclusive Breast Feeding Practice and Associated Factors among Under Six-Month-Old Children: J Nutr Heal Food Sci . 2017.

67. Teka B, Assefa H, Haileslassie K..Prevalence and determinant factors of exclusive breastfeeding practices among mothers in Enderta woreda , Tigray , North Ethiopia: Int Breastfeed J . 2015;1-7.

68. Biks GA, Tariku A, Tessema GA.Effects of antenatal care and institutional delivery on exclusive breastfeeding practice in northwest Ethiopia: Int Breastfeed Journal [Internet]. 2015;1-6. Available from: http://dx.doi.org/10.1186/s13006-015-0055-4

69. Liberati A, Altman DG, Tetzlaff J, Mulrow C, Gøtzsche PC, loannidis JPA, et al.The PRISMA Statement for Reporting Systematic Reviews and Meta-Analyses of Studies That Evaluate Health Care Interventions: plos Med. 2009;6(7).

70. The Joanna Briggs istitute.The Joanna Briggs Institute Reviewers ' Manual 2015 Methodology for JBI Scoping Reviews: 2015; Available from: www.joannabriggs.org

71. Rücker G, Schwarzer G, Carpenter JR, Schumacher M.Undue reliance on I 2 in assessing heterogeneity may mislead: BMC Med Res Methodol. 2008;9:1-9.

72. Borenstein M, Hedges L V, Higgins JPT, Rothstein HR.A basic introduction to fixed-effect and randomeffects models for meta-analysis: Res Synth methods. 2010;(August).

73. Shumetie G, Gedefaw M, Kebede A, Derso T. breastfeeding and rotavirus vaccination are associated with decreased diarrheal morbidity among under-five children in Bahir Dar, northwest Ethiopia: Public Heal Rev. 2018;1-10.

74. Kasahun AW, Wako WG, Gebere MW, Neima GH.Predictors of exclusive breastfeeding duration among 6 - 12 month aged children in gurage zone, South Ethiopia: Int Breastfeed J . 2017;1-9.

75. Minas AG, Ganga-limando M.Social-Cognitive Predictors of Exclusive Breastfeeding among Primiparous Mothers in Addis Ababa, Ethiopia: PLOSONE [Internet]. 2016;1-12. Available from: http://dx.doi.org/10.1371/journal.pone.0164128

76. Genetu H, Yenit MK, Tariku A.Breastfeeding counseling and support are associated with continuous exclusive breastfeeding from one week to six months of age among HIV exposed infants in north Gondar zone, Ethiopia: Int Breastfeed J . 2017;1-8.

77. A.Bekere,W.Garoma FB.Exclusive Breastfeeding Practices of HIV Positive mothers and its Determinants in Selected Health Institution of West Oromia , Ethiopia: J Nutr Food Sci. 2014; (September 2017). 
78. Alemayehu T, Haidar J, Habte D.Determinants of exclusive breastfeeding practices in Ethiopia: EthiopJHealth Dev.2009,23(1).

79. Abera K.Infant and Young Child Feeding Practices Among Mothers Living in Harar, Ethiopia: Harar Bull Heal Sci. 2012.

80. T.Setegn, T.Belachew.M.Gerbaba, K.Deribe, A.Deribew SB.Factors associated with exclusive breastfeeding practices among mothers in Goba district, south east Ethiopia: Int Breastfeed Journal. 2012;1-8.

81. Seid AM, Yesuf ME, Koye DN.Prevalence of Exclusive Breastfeeding Practices and associated factors among mothers in Bahir Dar city , Northwest Ethiopia: Int Breastfeed J . 2013;1-8.

82. Sefene A, Birhanu D, Awoke W, Taye T.Determinants of exclusive breastfeeding practice among mothers of children age less than 6 month in Bahir Dar city administration, Northwest Ethiopia: Sci J Clin Med. 2013;2(6):153-9.

83. Berhe $H$, Sciences H.DETERMINANTS OF BREAST FEEDING PRACTICES AMONG MOTHERS ATTENDING PUBLIC HEALTH FACILITIES, MEKELLE, NORTHERN ETHIOPIA: IJPSR. 2013;4(2):65060.

84. Taddele M, Abebe L, Fentahun N.Exclusive breastfeeding and maternal employment in Ethiopia: A comparative Exclusive breastfeeding and maternal employment in Ethiopia : Int J Nutr Food Sci. 2014.

85. Dachew BA, Bifftu BB.Breastfeeding practice and associated factors among female nurses and midwives at North Gondar Zone, Northwest Ethiopia: nternational Breastfeed J . 2014;1-7.

86. Hailu S, Wassie B, Jara D.Current Level and Correlates of Exclusive Breastfeeding among Employed Mothers in Debre Marko 's Town , Northwest Ethiopia: Community Med Heal Educ. 2014;4(5).

87. Woldie TG, Kassa AW, Edris M.Assessment of exclusive breast feeding practice and associated factors in Mecha district, North west Ethiopia; Sci J Public Heal. 2014;2(4):330-6.

88. W.Seifu, G.Assefa GE.Prevalence of Exclusive Breast Feeding and its Predictors Among Infants Aged Prevalence of Exclusive Breast Feeding and its Predictors Among Infants Aged Six Months: J Pediatr Neonatal Care Prevalence. 2014.

89. Alemayehu M, Abreha K, Yebyo H, Zemichael K.Factors associated with timely initiation and exclusive breast feeding among mothers of Axum town, Northern Ethiopia: Sci J Public Heal. 2014.

90. Alebel A, Tesma C, Temesgen B, Ferede A, Kibret GD.Exclusive breastfeeding practice in Ethiopia and its association with antenatal care and institutional delivery: a systematic review and meta-analysis: Int Breastfeed Journal. 2018;1-12.

91. Ranjbaran M, Nakhaei MR, Chizary M, Shamsi M.Prevalence of exclusive breastfeeding in Iran: Systematic review and meta-analysis: Int J Epidemiol Res. 2016;3(3).

92. Issaka Al, Agho KE.Prevalence of key breastfeeding indicators in 29 sub-Saharan African countries: a meta-analysis of demographic and health surveys ( 2010 - 2015): BMJ Open. 2017;1-10. 
93. Berde AS, Yalc S.Determinants of Exclusive Breast Feeding in sub-Saharan Africa: Paediatr Perinat Epidemiol. 2016.

94. Victor R, Baines SK, Agho KE, Dibley MJ.Determinants of breastfeeding indicators among children less than 24 months of age in Tanzania: a secondary analysis of the 2010 Tanzania Demographic and health survey: BMJ Open. 2013;1-8.

95. Rakotomanana H, Gates GE, Hildebrand D, Stoecker BJ.Situation and determinants of the infant and young child feeding ( IYCF ) indicators in Madagascar: analysis of the 2009 Demographic and Health Survey: BMC Public Heal. 2017;1-9.

96. Lauer JA, Betrán AP, Victora CG, Onís M De, Barros AJD.Breastfeeding patterns and exposure to suboptimal breastfeeding among children in developing countries: BMC Med. 2004;29.

97. Arifeen S, Black RE, Antelman G, Baqui A, Caulfield L, Becker S, et al.Exclusive Breastfeeding Reduces Acute Respiratory Infection and Diarrhea Deaths Among Infants in Dhaka Slums: Pediatrics.2001.

98. Beatriz M, Nascimento R, Reis MAM, Franco SC, Issler H, Ferraro AA, et al.Exclusive Breastfeeding in Southern Brazil,prevalence and associated factors: Breastfeed Med. 2010;5(2).

99. Hamade H, Chaaya M, Saliba M, Chaaban R, Osman H.Determinants of exclusive breastfeeding in an urban population of primiparas in Lebanon: BMC Public Heal.2013.

100. T.Amin,H.Hablas AQ.Determinants of Initiation and Exclusivity of Breastfeeding in Al hassa,saudi arabia: Breastfeed Med. 2011;6(2):10-2.

101. Radhakrishnan S, Balamuruga SS.Prevalence of exclusive breastfeeding practices among rural women in Tamil Nadu: Int J Heal Allied Sci. 2012;1(2).

102. Jessri M, Farmer AP, Maximova K, Willows ND, Bell RC.Predictors of exclusive breastfeeding: observations from the Alberta pregnancy outcomes and nutrition ( APrON) study: BMC Pediatr. 2013.

103. Alzaheb RA.Factors Influencing Exclusive Breastfeeding in Tabuk, Saudi Arabia: Clin Med Insights. 2017.

104. Ogbo FA, Dhami MV, Awosemo AO, Olusanya BO, Olusanya J, Osuagwu UL, et al.Regional prevalence and determinants of exclusive breastfeeding in India: Int Breastfeed J . 2019;0:1-12.

105. Khanal V, Sauer K, Zhao Y.Exclusive breastfeeding practices in relation to social and health determinants: a comparison of the 2006 and 2011 Nepal Demographic and Health Surveys: BMC Public Heal. 2013.

106. Tampah-naah AM, Kumi-kyereme A.Determinants of exclusive breastfeeding among mothers in Ghana: Int Breastfeed Journal. 2013;2-7.

107. The Federal Democratic Republic of Ethiopia, Ministry of Health. Health Sector Transformation Plan(HSTP) 2015/16 - 2019/20.2015.

108. M.Saffari $M$, Pakpour $A H$, Chen H.Factors influencing exclusive breastfeeding among Iranian mothers: A longitudinal population-based study: Heal Promot Perspect [Internet]. 2017;7(1):34-41. Available from: http://dx.doi.org/10.15171/hpp.2017.07 
109. Tan KL.Factors associated with exclusive breastfeeding among infants under six months of age in peninsular malaysia: Int Breastfeed J 2011. 2011;1-7.

110. Mohamed AA, Mohamud SA, Mohamud FY, Ali KA, Abdulle FA, Hussein AA.Prevalence and Associated Factors of Exclusive Breastfeeding Practices Among Mothers of Infants Less Than Six Months in Galkayo, Somalia: Sci J Public Heal. 2018;6(5).

111. Xiang N, Zadoroznyj M, Tomaszewski W, Martin B.Timing of Return to Work and Breastfeeding in Australia: 2016.

112. Navarro-rosenblatt D.Maternity Leave and Its Impact on Breastfeeding, review of the literature: Breastfeed Med.2018.

113. Steurer LM.Maternity Leave Length and Workplace Policies ' Impact on the Sustainment of Breastfeeding ,Global Perspectives: Public Heal Nursing,. 2017;34(3):286-94.

114. Chai Y, Nandi A, Heymann J.Does extending the duration of legislated paid maternity leave improve breastfeeding practices? Evidence from 38 low-income and middle-income countries: BMJ Glob Heal. 2018;1-14.

\section{Additional File Legends}

Additional file1: table S1: Descriptive summary of 36 studies included in the meta-analysis of the prevalence of exclusive breastfeeding in Ethiopia, 2019.

Additional file2:PRISMA 2009 check list that insure uniformity of systematic review.

\section{Figures}




\section{PRISMA 2009 Flow Diagram}

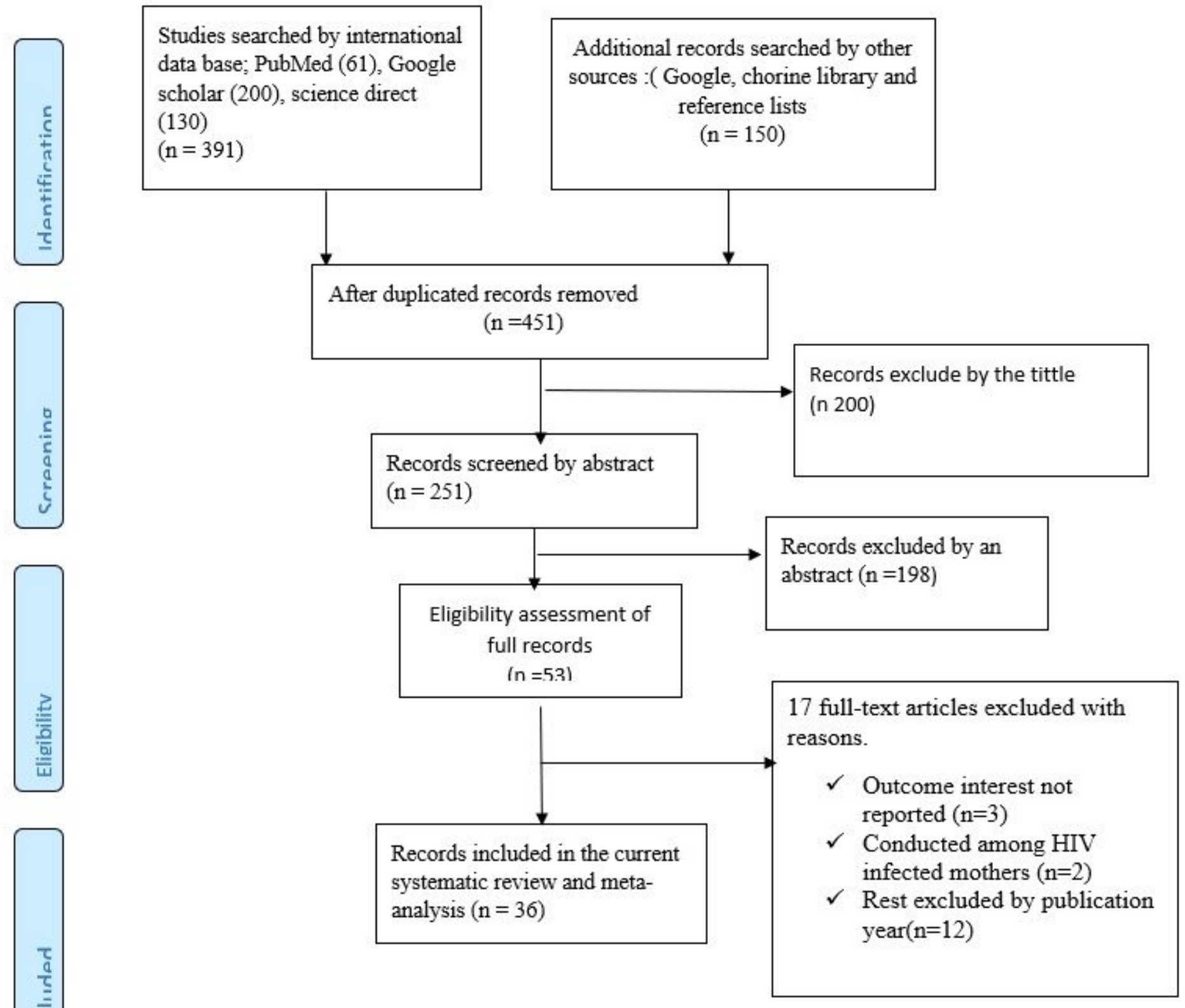

\section{Figure 1}

Flow diagram of studies included in systematic review and meta-analysis, 2019. 


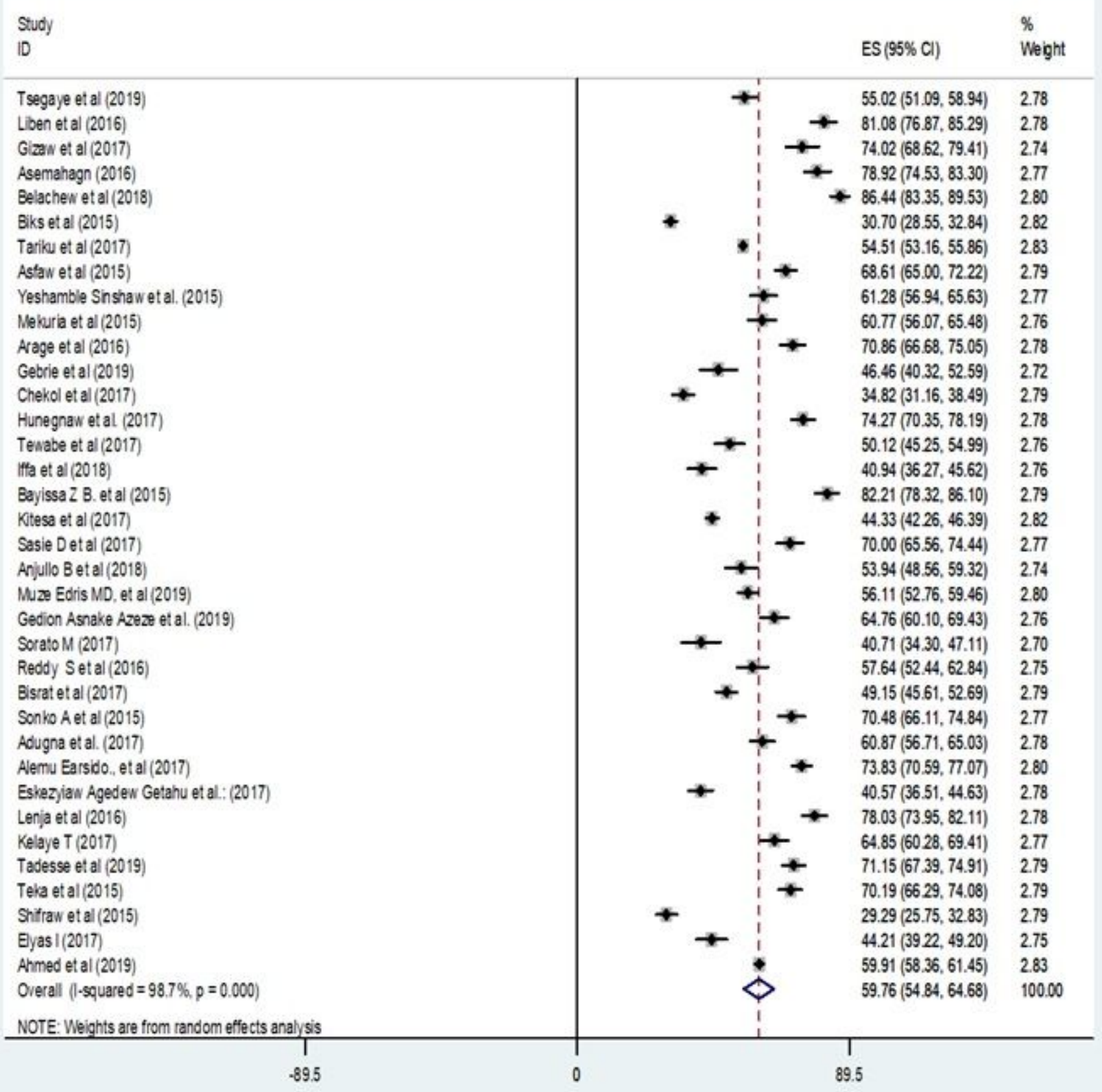

\section{Figure 2}

Forest plot displaying the pooled prevalence of exclusive breastfeeding of 36 studies in Ethiopia, 2019. 
Tarinu et a (2017-2019)

Gebrie of al (2017-2019)

Chekol et a (2017-2019)

Henegnaw et al (2017-2019)

Tewabe ef a (2017-2019)

Iffa et al (2017-2019)

Klesa et al (2017.2019)

Sase D et al (2017.2019)

Anjulo $B$ et al (2017-2019)

Muze Edris MD, et al (2017-2019)

Gedon Asnake Azeze ef al. (2017-2019)

Sorato M (2017-2019)

Bsat et al (2017-2019)

Adugna et al (2017-2019)

ANemu Earsido, et al (2017-2019)

Eskezyiaw Agedew Getahu et a: : (2017-2019)

Kelaye T (2017-2019)

Tadesse et al (2017-2019)

Byas I (2017-2019)

Ahmed et al (2017-2019)

Subtctal 0 -squared $=98.1 \%, p=0.000$ )

2015.2016

Liben et a (2015-2016)

Asemahagn (2015-2016)

Biks et al (2015-2016)

Astaw et al (2015-2016)

Yestamble Sinshaw et al. (2015-2016)

Mekuria ef al (2015-2016)

Avage et a (2015-2016)

Bayissa Z B et al (2015-2016)

Redd) Set al (2015-2016)

Sorko A et al (2015-2016)

Lenja et al (2015-2016)

Teka et al (2015-2016)

Shitraw et a (2015-2016)

Sustctal (p-squared $=99.2 \%, p=0.000$ )

Overal (l-squared $=98.7 \%, p=0.000$ )

NOTE Weights are from random effects analysis

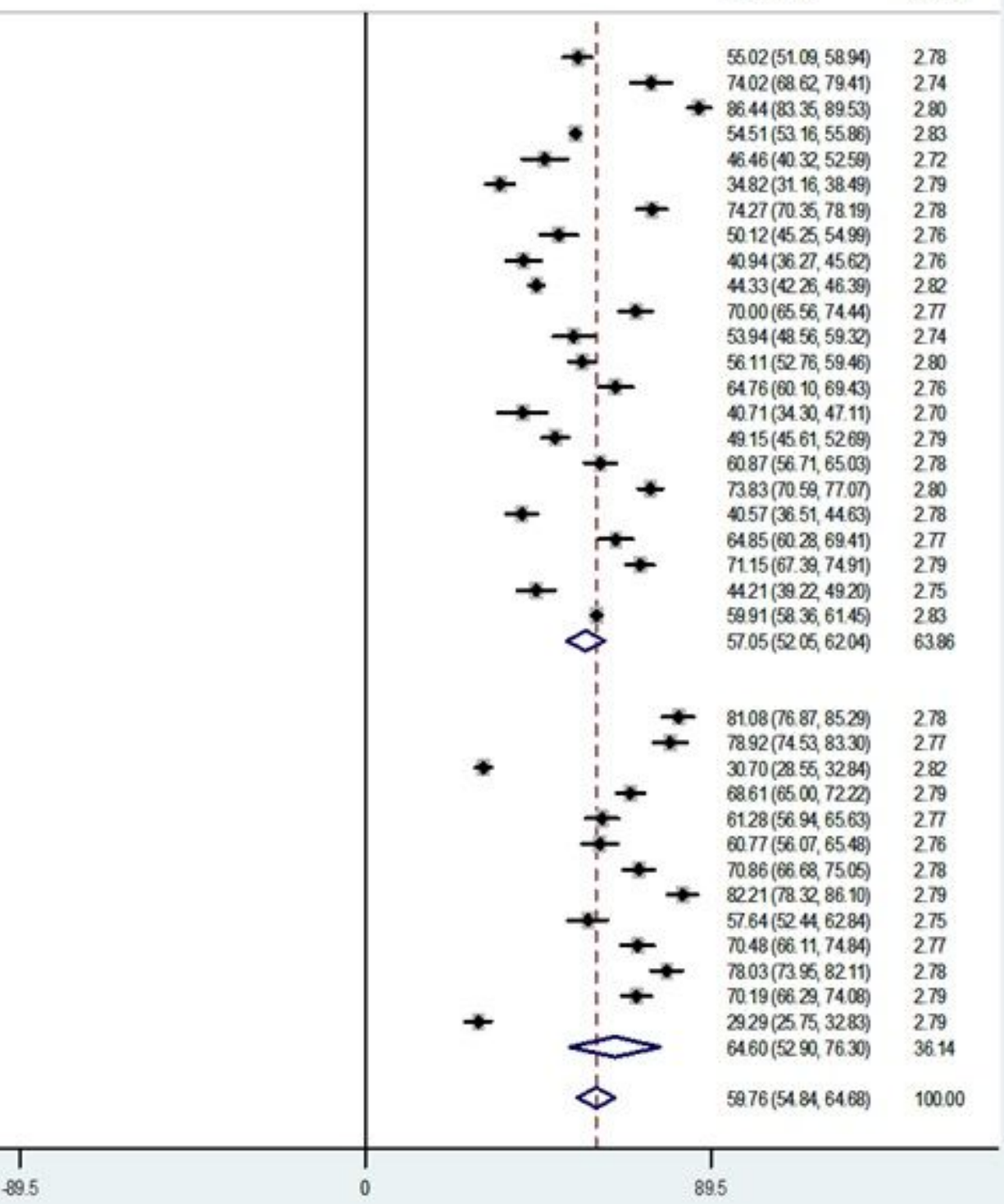

\section{Figure 3}

The subgroup analysis for the prevalence of exclusive breastfeeding by year of publication in Ethiopia, $2019(n=36)$. 


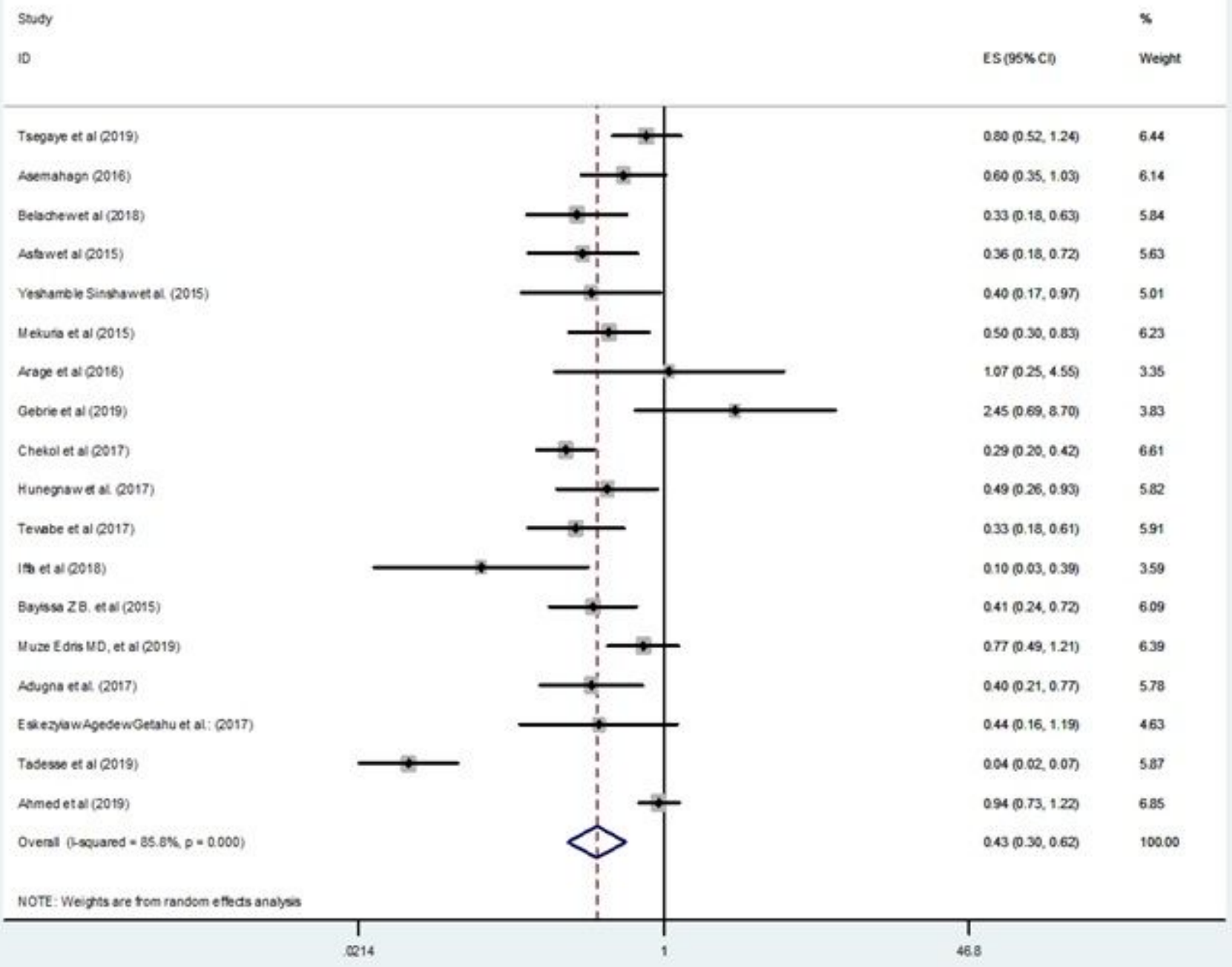

Figure 4

The pooled odds ratio of the association between maternal employment and exclusive breastfeeding in Ethiopia in 2019. 


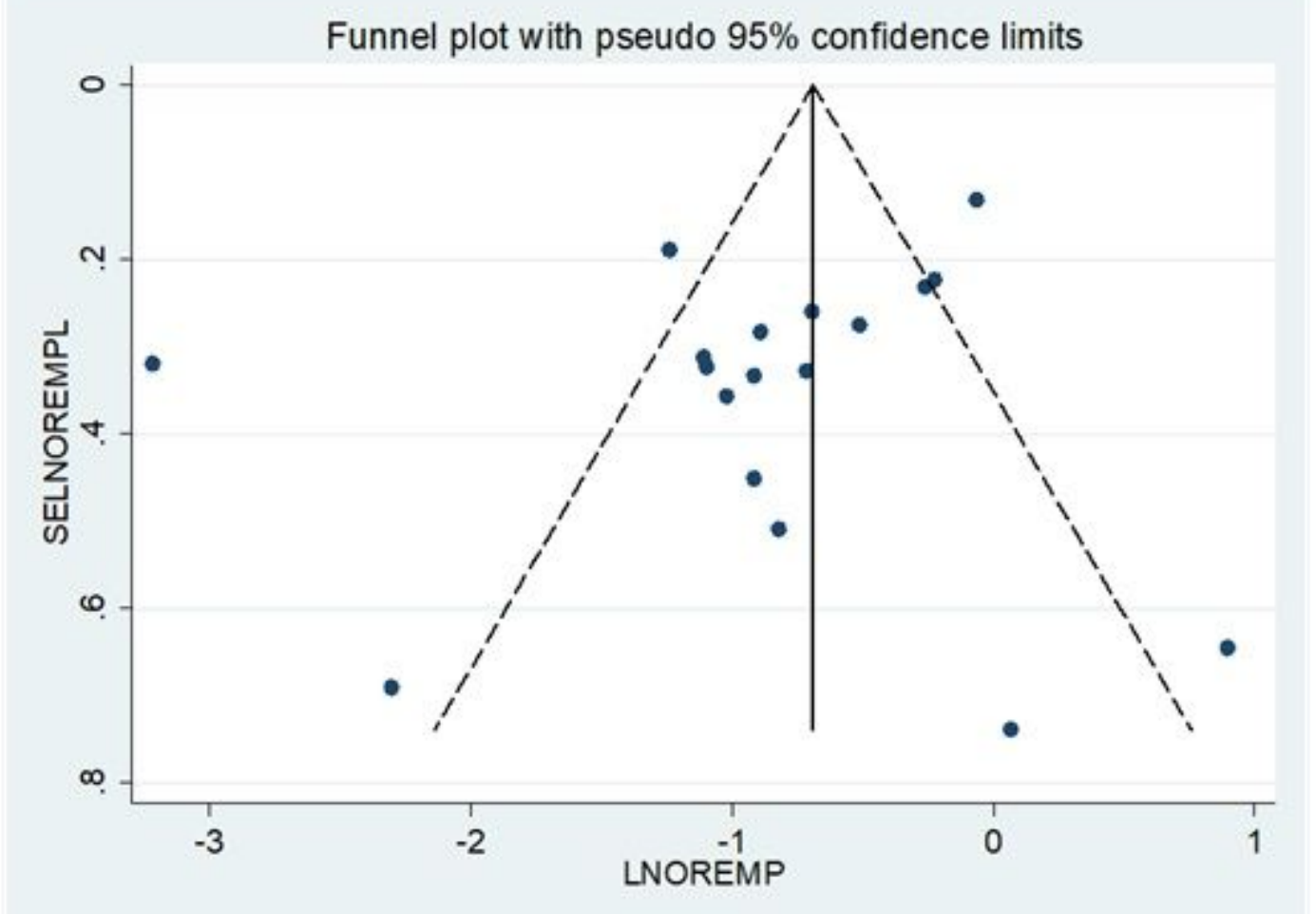

Figure 5

Funnel plot for publication bias, LNOREMP represented in the $x$-axis and standard error of LNOREMP on the $y$-axis

\section{Supplementary Files}

This is a list of supplementary files associated with this preprint. Click to download.

- additionalfile2PRISMA2009checklist.doc

- additinalfiles1..docx 